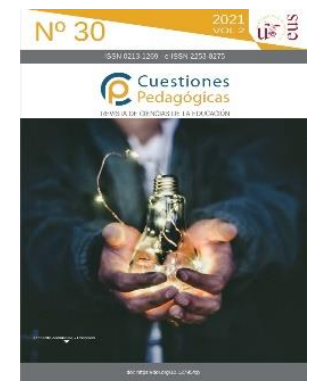

\title{
Globalización y aculturación: la influencia de los medios de comunicación en la Educación Intercultural de Ecuador
}

\section{Globalization and Acculturation: Influence of the Media in Ecuadorian Intercultural Education}

Resumen: El objetivo principal del artículo es analizar críticamente el impacto de la globalización en los procesos de construcción de la identidad ecuatoriana. La metodología utilizada es exploratoria, descriptiva, aplicada y comparativa, con el fin de identificar la influencia propagandística e ideológica que ejercen los medios de comunicación globalizados en la aculturación de los adolescentes ecuatorianos. En este sentido, se toma una muestra de dos escuelas del milenio, dos públicas y dos privadas de la ciudad de Cuenca. Las técnicas e instrumentos utilizados son la encuesta exploratoria y la tabulación de resultados por medio del programa estadístico SPSS, y están fundamentadas en las cinco ecologías de saberes, temporalidades, reconocimientos, transescalas y productividades propuestas por Santos para resistir a la influencia mediática en los contextos escolares interculturales. Como resultado, se discuten e interpretan los datos recopilados en las encuestas mediante el
Abstract: The main objective of the article is to critically analyze the impact of globalization on the processes of construction of the Ecuadorian identity. The methodology used is exploratory, descriptive, applied and comparative, in order to identify the propaganda and ideological influence exerted by the globalized media in the interculturalization of Ecuadorian adolescents. In this sense, a sample of two millennium schools is taken, along other two public and two private in the city of Cuenca. The techniques and instruments used are the exploratory survey and the tabulation of results using the SPSS statistical program, which are based on the five ecologies of knowledge, temporalities, recognitions, trans-scales and productivities proposed by Santos to resist media influence in intercultural school contexts. As a result, the data collected in the surveys are discussed and interpreted through the competencies, abilities and skills approach established by the National Curriculum of the Unified General Baccalaureate (BGU) to promote a critical and inclusive intercultural education in Ecuador. To 
enfoque de competencias, habilidades y destrezas que establece el Currículo Nacional de Bachillerato General Unificado (BGU) para promover una educación intercultural crítica e inclusiva en Ecuador. Para concluir, se reflexiona críticamente desde una visión intercultural emancipadora que concibe la identidad como un fenómeno socio-espacialcomunicacional, permitiendo la deconstrucción de conceptos y significados construidos por la globalización. conclude, it critically reflects from an emancipating intercultural vision that conceives identity as a socio-spatial-communicational phenomenon, allowing the deconstruction of concepts and meanings built by globalization.
Palabras clave: Aculturación, educación intercultural, globalización, identidad, medios de comunicación.
Keywords: Acculturation, intercultural education, globalization, identity, media.

\section{Introducción}

En Ecuador, el estudio de la identidad sigue siendo un debate académico en construcción por su gran complejidad y diversidad. Como antecedente, el carácter intercultural, plurinacional y multiétnico de la ciudadanía ecuatoriana viene siendo abordado desde la antropología, la historia, la sociología, las artes, la filosofía, la geografía humana y la educación, entre otros campos del saber (Echeverría, 1995; Dietz, 2012; Tubino, 2005; Waldmüller, 2016; Zebadúa, 2011). Al no existir un consenso científico, esta investigación empírica busca contribuir al debate académico de la educación intercultural desde un análisis crítico y comparativo, al tomar como muestra dos escuelas del milenio, dos públicas y dos privadas que no se integran en el conjunto de centros escolares de Sistema de Educación Intercultural y Bilingüe (SEIB). Las técnicas e instrumentos utilizados son la encuesta exploratoria y la tabulación de resultados por medio del programa estadístico SPSS.

La investigación aborda los procesos de aculturación que se dan en estos seis centros educativos de Cuenca, con el fin de identificar y definir las relaciones que tienen los estudiantes de 16 a 18 años con la propaganda comercial e ideológica que publicitan los medios de comunicación, puesto que influencian y determinan su construcción identitaria. Por este motivo, el trabajo se vertebra desde un eje de enunciación epistémico que unifica la educación intercultural y las ciencias de la comunicación. Esta combinación epistemológica estudia la influencia en la construcción identitaria de los adolescentes ecuatorianos con respecto a los fenómenos colonizadores desplegados por los medios de comunicación mediante industrias culturales, información de consumo masivo y semiótica articulada de la publicidad (Yalán, 2019). 
En los últimos años, se viene observando que el uso masivo de dispositivos móviles con acceso a internet ha invisibilizado y desvalorizado las distintas culturas, ritos, tradiciones y costumbres populares de la ciudadanía heterogénea (Muñoz, 2016). Por eso el problema de investigación diagnosticado es la pérdida de rasgos culturales e identitarios de los adolescentes ecuatorianos como consecuencia de la aculturación provocada por la influencia mediática, propagandística e ideológica que ejercen las empresas transnacionales en los medios de comunicación de masas. A su vez, se generan las siguientes preguntas de investigación: ¿Cómo afecta la globalización en la construcción de la identidad en los estudiantes? ¿Cómo se enseña y comunica la educación intercultural en el contexto escolarizado de $3^{\circ}$ de Bachillerato?

Con estas cuestiones de fondo, el artículo tiene el objetivo general de analizar el impacto de la globalización en la construcción de la identidad intercultural ecuatoriana. Para tal fin, se analiza la literatura especializada para explorar cómo los avances de la informatización y de las tecnologías de la información y comunicación (TIC) han privilegiado los estereotipos publicitarios de las corporaciones transnacionales en detrimento de la idiosincrasia intercultural de pueblos y naciones. Según denuncian intelectuales como Castells (2010), Chomsky (2002), Dussel (2013), Estermann (2014), Mignolo (2012), Quijano (2000), Shiva y Shiva (2020) o Wallerstein (2011), la globalización económica ha permitido la 'universalización' de la cultura occidental al resto del planeta: presentándose como el mejor modelo de progreso y desarrollo.

En efecto, todavía no se ha producido un debate serio, crítico y profundo que cuestione los pilares epistémicos en los que se fundamentan organismos internacionales como el Banco Mundial (BM), el Fondo Monetario Internacional (FMI) o la Organización de las Naciones Unidas (ONU). Para Stiglitz, Sen y Fitoussi (2010), estas instituciones no cuestionan el carácter occidental, modernista, capitalista y antropocéntrico del concepto de 'desarrollo' que promueven. Según explican Castells y Hall (2014), estas organizaciones internacionales tampoco cuestionan la enorme acumulación de capital y recursos concentrados en las manos de complejos industriales que conforman tecnopolis e imposibilitan reducir la desigualdad social en el mundo.

Para McCarthy (2017), es necesario cuestionar los límites del crecimiento económico y del poder geopolítico que tienen las empresas transnacionales para controlar y monopolizar los mercados, especialmente cuando Google, Facebook, Instagram, TikTok y otras apps personalizan los anuncios comerciales según los datos obtenidos, de manera voluntaria, por los usuarios. Así es como asistimos ante la mayor manipulación de masas de la historia humana, basada en la Big Data que la ciudadanía fornece a complejos algoritmos matemáticos que nutren a programas de inteligencia artificial (Levitskaya y Fedorov, 2020; van Dijk, 2011). Así lo expone el documental 'Nada es privado' (The Grate Hack) de Karim Amer y Jehane Noujaim, 
que muestra el caso de Cambridge Analytica, explicando cómo la Big Data y la inteligencia artificial han sido utilizadas para influenciar en las decisiones políticas del mundo: logrando influenciar en la elección de presidentes de varios países. De este modo, el fenómeno de manipulación global tiene una fuerte influencia en la esfera socio-educativa, ya que los adolescentes son más vulnerables que otros sectores poblacionales (Haydon, 2020).

De ahí la necesidad de repensar los procesos de interculturalización de los pueblos frente a los procesos de aculturación de la globalización en los contextos educativos. Si bien este artículo representa una pequeña muestra que indaga la situación fenomenológica y hermenéutica de seis escuelas de la ciudad de Cuenca, en Ecuador, se justifica por su búsqueda de revalorizar las costumbres, cosmovisiones, prácticas y raíces identitarias de los distintos pueblos, culturas y nacionalidades que conforman un Ecuador diverso (INEC, 2010).

\section{Estado de la cuestión y revisión de la literatura especializada}

En este nuevo contexto político y económico originado por el COVID-19, la educación virtual se ha puesto en el centro del debate académico, proliferando numerosas investigaciones que valoran diferentes softwares y apps que permiten la interacción en esta modalidad de enseñanza-aprendizaje (Pesántez, Álvarez y Torres, 2021). En Ecuador, el Ministerio de Educación formuló el Plan Educativo COVID-19: Aprendiendo Juntos en Casa, con el objetivo de proseguir con la educación inicial, básica y bachillerato en la modalidad virtual. Esta transición evidenció una tremenda brecha social que excluye a miles de estudiantes, que no han podido continuar con sus estudios por la falta de recursos materiales que les permitiesen seguir las clases (Vivanco, 2020). Según el informe presentado por la Comisión Broadband de la UNESCO (2020), más de 3,600 millones de personas en el mundo no tienen acceso a internet, y se estima que 250 millones de niños están fuera de las escuelas.

En Latinoamérica, la situación es especialmente preocupante en las zonas rurales y periféricas de las ciudades, que carecen de medios y recursos que les permitan acceder al derecho de la educación. En Ecuador, el Instituto Nacional de Estadística y Censo (INEC, 2019) desarrolló una encuesta nacional multipropósito de hogares en diciembre de 2019 , donde se constató que tan solo el $23,28 \%$ de las familias contaba con computadoras de escritorio; el $28,47 \%$ con computadoras portátiles; el 11,17\% con computadora de escritorio y portátil; el 35,57\% con telefonía fija y el $91,01 \%$ con telefonía celular. Ante esta brecha socio-económica, resulta evidente que los Estados-Nación deben incrementar las políticas públicas que aseguren la calidad educativa, al mismo tiempo que forman continuamente al cuerpo docente para adaptarse a un mundo cambiante, virtual y globalizado.

En este sentido, Santos (2020) argumenta que la situación pandémica del 2020 ha servido para visibilizar la monopolización que las corporaciones vienen 
desarrollando a escala global desde hace décadas. Los medios de comunicación globales están asociados a grandes grupos de poder que actúan en consorcios económicos que integran al sector bancario, agrícola, inmobiliario, energético y petrolífero (Klein, 2019). Según denunció el informe de Reporteros sin Fronteras (2016), el 70\% de la oferta comunicativa global está en manos de tan solo seis corporaciones mediáticas: The Walt Disney, Time Warner, News Corp, 21st Century Fox, Viacom-cbs y Vivendi-nbs Universal. El informe señala que estas corporaciones controlan más de 1.500 periódicos, 1.100 revistas, 2.400 editoriales, 9.000 radios y 1.500 cadenas de televisión.

Por esta razón, González (2020) denuncia que la información que se publica en los medios de comunicación globalizados está al servicio de las élites plutocráticas del capitalismo global. Estas investigaciones explican cómo los intereses geopolíticos de estas corporaciones controlan las noticias periodísticas y la propia libertad de información. De acuerdo a la investigación de Gupta (2012), esta monopolización genera procesos de aculturación que moldean el imaginario colectivo y la identidad individual de aquellas personas más vulnerables, como son los niños, jóvenes y adolescentes que todavía no han desarrollado un pensamiento crítico sobre el mundo que les rodea. Este proceso de aculturación también es denominado como la 'monocultura de la mente' por Shiva (1993), al privilegiar los rasgos culturales occidentales frente a los propios de las comunidades, pueblos y nacionalidades.

Aquí resultan esclarecedores los estudios pioneros de Swimme (1996), al verificar que los niños y jóvenes de Norteamérica pasan más tiempo asistiendo anuncios comerciales que en la escuela. Según sus estudios, llegan a consumir, de media, unos treinta mil anuncios antes de llegar al primer grado de su educación. Al ser influenciados desde edades tan tempranas, resultan incapaces de percibir la colonialidad epistémica y cultural que sufren con la publicidad que difunden los medios de comunicación. Con el uso masivo de las TICs, se ha incrementado exponencialmente la difusión de estos medios, cuyos contenidos responden a los intereses comerciales de los mercados y lobbies globales (Becerra y Mastrini, 2017). De manera similar, las investigaciones desarrolladas por el educador ambiental David Orr (1999), apuntan que un habitante medio de Estados Unidos es capaz de reconocer más de mil logos de empresas corporativas y menos de diez especies autóctonas de la región en la que habita.

Pero ¿será que en Ecuador sucede lo mismo? ¿Cuál es la influencia de los medios de comunicación y las TICs en la formación identitaria de los adolescentes? ¿Cómo puede la educación intercultural confrontar la desvalorización de la identidad cultural causada por la globalización? Si bien no existen recetas mágicas o respuestas categóricas a estas preguntas, en las siguientes líneas se exponen argumentos para dar luz a la cuestión. 


\section{La globalización en la educación y los problemas identitarios}

La educación es un ámbito social que debe promover y fortalecer una conciencia crítica sobre el modus operandi desplegado por la globalización a través de medios de comunicación y TICs. Según explica Castells (2013), la información es sinónimo de poder en la era de la globalización, ya que los algoritmos matemáticos empleados por la inteligencia artificial coaccionan la libertad de los ciudadanos: limitando la información mostrada mediante índices de indexación de los buscadores (Google, Bing, Yahoo, etc.). Dicho en otras palabras, aquellas compañías que pagan para publicitar sus servicios en las plataformas de búsqueda aparecen en las primeras posiciones de los buscadores de información de internet, por lo que no solo logran una ventaja competitiva con el resto de las empresas que no aparecen en las primeras páginas de búsqueda, sino que también logran monopolizar su contenido entre los usuarios (Haucap y Heimeshoff, 2014).

Por tanto, internet no muestra información relacionada con el conocimiento local o la sabiduría de la comunidad desde donde se ejerce la búsqueda, sino una información sesgada, comercial y distante para el crecimiento personal, que también genera procesos de aculturación y monocultura de la mente (Ozer et al. 2017). Podría afirmarse que la globalización perjudica gravemente al sistema educativo, principalmente en lo que se refiere a la construcción cultural e identitaria. Según advierten Berger y Huntington (2002), la globalización provoca la homogenización cultural de la ciudadanía. Al homogeneizar la cultura, también se homogeniza la identidad, los valores y las formas de sentir, pensar y actuar de las personas.

Por eso Gómez (1999) defiende que "la educación es el pasaporte de los individuos y de las naciones a la sociedad del conocimiento y a la aldea global" ( $p$. 42). Pero esto implica repensar profundamente las políticas públicas educativas a escala multinivel. Efectivamente, el mundo globalizado actual demanda nuevas competencias, destrezas y habilidades para que los estudiantes puedan aprender, desaprender y volver a reaprender mediante un pensamiento crítico y plural que les permita construir su identidad cívica sin sufrir los efectos de la aculturación. En Ecuador, Cuche (2007) ha analizado los problemas identitarios, señalando:

Las estrategias identitarias pueden manipular e incluso modificar una cultura, que incluso ya no tendrá mucho en común con lo que tenía antes. La cultura releva en gran parte de procesos inconscientes, mientras que la identidad remite a una norma de pertenencia necesariamente consciente, al fundarse sobre oposiciones simbólicas (p.83).

Al formar parte de la sociedad de la información, los estudiantes sufren un constante bombardeo de información por diversos canales: TV, apps, TICs y servicios de internet que los medios de comunicación utilizan para divulgar sus contenidos comerciales. Parafraseando a Derrida (2021), podría decirse que este proceso 
globalizador viola transcendentalmente la identidad e imaginario colectivo de los estudiantes y comunidades educativas. De este modo, se logran imponer los estereotipos publicitarios del capitalismo como modelos a seguir e imitar para estar 'bien vistos socialmente'. Esta situación origina que los estudiantes rechacen sus propias culturas, y utilicen vocablos como 'cholos' o 'indio' para referirse de manera peyorativa y degradante a los que optan por mantener sus raíces culturales locales. Así, surge una ciudadanía global híbrida que integra distintos aspectos culturales de los pueblos.

Dentro de este enfoque, existen pocas investigaciones que aborden la forma en que la globalización modifica la conducta de los adolescentes para desarrollar y construir su identidad, a pesar de que todo parece indicar que se producen imposiciones identitarias que logran privilegiar las costumbres extranjeras. Para Naval (2001), la globalización es "una amenaza para la diversidad cultural" (p.23) que provoca problemas identitarios y moldea estructuras mentales entre los más jóvenes. De forma similar, Barbero y Rey (2000) aducen que los medios de comunicación despliegan tendencias, ideologías y formas culturales que pasan a formar parte de la cotidianidad de los estudiantes.

Entonces, resulta necesario reconocer que la hibridación cultural forma parte de este proceso de construcción de la identidad, donde lo local y tradicional se altera ante el fenómeno global mediante diferentes escenarios culturales. Aquí se produce la convergencia de los procesos políticos, económicos y sociales de las sociedades hacia un mismo modelo capitalista. Para Aguado, Melero, y Gil-Jaurena (2018) la hibridación intercultural se puede concebir como una identidad construida a través de una negociación de la diferencia, al comprender que todas las culturas son hibridaciones de culturas anteriores. Rivera (2010) también señala que la identidad es un concepto híbrido y transformador que se deconstruye y reconstruye constantemente.

En este sentido, Fariñas (2005) afirma que la actual globalización cultural es la dimensión prescriptiva y normativa de la globalización económica, que la utiliza para alcanzar su dominio imperial y totalizador. Para este autor, la globalización cultural representa el aspecto más profundo de la dominación, porque penetra en la vida íntima de las personas y destruye su originalidad e identidad. Aquí resulta urgente y necesario que los educadores podamos diseñar e implementar estrategias pedagógicas de concientización social sobre el rol que desempeñan los medios globalizados en el comportamiento de las personas. Debemos explicar que estos medios tecnológicos y digitales buscan captar la atención de los jóvenes mediante recursos publicitarios que les permite conocer mejor a los usuarios, para después seguir ofreciéndoles más contenidos similares de otras empresas, que son las que compran la Big Data para ofrecer nuevos servicios y productos. Un negocio muy lucrativo que en 2018 batió todos los records, generando más de 31 billones de dólares, con pronósticos de 144 billones para 2026 (Reports \& Data, 2020). 
Pero ¿cómo podemos explicar a los jóvenes adolescentes que pasen menos horas en sus celulares? ¿Cuál es el papel de los docentes y padres de familia para advertirles de los peligros de colonialidad epistémica que sufren al usar las apps de moda? ¿Cómo explicarles que la identidad intercultural de los pueblos y nacionalidades de Ecuador se ve afectada por el consumo masivo de una información que homogeniza y aculturiza? Como se explica a continuación, la metodología empleada se enfocó en identificar las preferencias culturales que tienen los estudiantes de la ciudad de Cuenca.

\section{Metodología y análisis de resultados}

La investigación ha desarrollado un enfoque cuantitativo de alcance exploratorio, descriptivo, aplicado y comparativo, con la finalidad de obtener datos relevantes sobre la influencia de la globalización en la educación intercultural, que ha sido poco estudiada por la literatura académica especializada. Como muestra la Tabla 1, la selección de la muestra se realizó mediante una muestra aleatoria no probabilística que eligió a estudiantes del Tercer año de Bachillerato General de seis escuelas: dos públicas, dos privadas y dos del milenio. Tras gestionar los permisos necesarios en el Distrito Educativo Zona 6 de la ciudad de Cuenca para la obtener la autorización, se conversó con los directores de los seis centros educativos y se ejecutó un cronograma con las encuestas exploratorias.

\section{Tabla 1.}

Muestra de estudiantes en las escuelas seleccionadas.

Unidades Educativas

\begin{tabular}{ll|c}
\hline Unidades Educativas & Unidad Educativa Herlinda Toral & 58 \\
\cline { 2 - 3 } & Unidad Educativa Dolores J. Torres & 44 \\
\hline \multirow{2}{*}{$\begin{array}{l}\text { Unidades Educativas } \\
\text { Privadas }\end{array}$} & Unidad Educativa Particular Mariana de Jesús & 76 \\
\cline { 2 - 3 } & Unidad Educativa Particular Sagrados Corazones & 60 \\
\hline Unidades del Milenio & Unidad Educativa del Milenio Manuel J. Calle & 68 \\
\cline { 2 - 3 } & Unidad Educativa del Milenio Sayausí & 40 \\
\hline & \multirow{2}{*}{ Total } & $\mathbf{3 4 6}$
\end{tabular}

Fuente: Elaboración propia

El instrumento de investigación seleccionado fue el cuestionario, que se estructuró siguiendo las cinco ecologías propuestas por Santos (2010) para combatir la monocultura de la globalización:

1) la ecología de saberes, fundamentada en que ningún conocimiento es completo y total, por lo que combatir la lógica de la monocultura conlleva un diálogo entre los conocimientos científicos y los saberes artísticos, espirituales, indígenas, etc. 
2) la ecología de las temporalidades, que entiende la idea del tiempo lineal como una forma lógica más entre las diferentes concepciones que existen en otras culturas, como es el tiempo cíclico, el tiempo circular, etc.

3) la ecología de los reconocimientos, que enfrenta la lógica de la clasificación social, sustentada en la colonialidad y el patriarcado, para que distintos grupos humanos tengan los mismos derechos y obligaciones.

4) la ecología de las transescalas, confronta la lógica de escala dominante para identificar las relaciones de inter-retro-actividad entre diferentes escalas locales, nacionales, regionales y globales.

5) la ecología de las productividades busca superar la lógica de productividad capitalista para recuperar y revalorizar otras formas de producción alternativas, como las cooperativas de trabajadores, proyectos de economía solidaria, microcréditos, empresas autogestionadas, etc.).

En su conjunto, se escogieron estas cinco ecologías porque buscan una apertura epistémica genuina que permita construir otras formas de sentir, pensar, estar, percibir, ser y actuar. Para Collado y Apolo (2018), estos cinco postulados epistemológicos constituyen la base para repensar la educación intercultural en las prácticas docentes cotidianas. Para enfrentar la aculturación de la globalización se necesita actuar con creatividad, innovación, convicción, compromiso social y predisposición de la comunidad educativa. De ahí que la encuesta se realizase de forma física, con el fin de explorar, aplicar, describir y comparar los resultados de las 31 preguntas del cuestionario (véase la Tabla 2). Cabe resaltar que las preguntas 1 , $16,21,22,23,24,25,31$ se refieren a la ecología de saberes. Las preguntas 28 y 29 hacen alusión a la ecología de las temporalidades. Las preguntas 2, 3, 4, 5, 6, 10, 11 , $12,13,14,15,19,20$ y 26 a la ecología de los reconocimientos. Las preguntas 7,8 y 9 a la ecología de las transescalas. Por último, las preguntas 17, 18, 27, 28 y 30 se enfocan en la ecología de las productividades.

La estructura de la encuesta permitió recoger aspectos generales y específicos sobre cómo influencia la globalización en el desarrollo de la identidad ecuatoriana de los estudiantes. Cabe destacar que la encuesta se realizó dos semanas antes de que los estudiantes rindiesen el examen de acceso a la universidad, por lo que se denotó nerviosismo, preocupación y estrés. Con el fin de evaluar la confianza y la fiabilidad de este instrumento, se contó con el apoyo de un experto en Educación Intercultural, que facilitó el análisis comparativo entre la monocultura globalizadora y la interculturalidad ecuatoriana.

Una vez obtenida la información con la debida aplicación del instrumento de investigación, se procedió a analizar los datos mediante la tabulación de los datos obtenidos. Para ello se utilizó el software SPSS (Statistical Package for the Social Sciences o Soporte Estadístico para las Ciencias Sociales), versión 20, de acuerdo a las variables establecidas en la encuesta. Esta tabulación nos permite analizar de forma descriptiva y comparativa las variables categóricas que estructuraban el 
instrumento de recogida de datos, generando tablas de frecuencias sobre los datos obtenidos.

Como resultado, podría decirse que la encuesta exploratoria constituye una primera indagación acerca de la convergencia entre la educación y los medios de comunicación. Otro resultado destacado es que se ha logrado identificar tendencias de comportamiento cultural que ponen de manifiesto la colonialidad causada por la globalización. En la Tabla 2 se muestran las respuestas mayoritarias que los 346 estudiantes de las seis Unidades Educativas dieron a cada una de las preguntas del cuestionario.

Tabla 2.

Resultados genéricos de la encuesta

\begin{tabular}{|c|c|c|c|c|c|c|c|}
\hline & & & & & & \\
\hline & & \multicolumn{2}{|c|}{ U.E. PÚBLICAS } & \multicolumn{2}{|c|}{ U.E. DEL MILENIO } & \multicolumn{2}{|c|}{ U.E. PRIVADAS } \\
\hline $\begin{array}{c}\text { Preguntas de la } \\
\text { encuesta } \\
\text { exploratoria }\end{array}$ & $\begin{array}{l}\text { Respuestas } \\
\text { mayoritarias }\end{array}$ & $\begin{array}{l}\text { Unidad } \\
\text { Educativa } \\
\text { Dolores } \\
\text { J. Torres }\end{array}$ & $\begin{array}{l}\text { Unidad } \\
\text { educativa } \\
\text { Herlinda } \\
\text { Toral }\end{array}$ & $\begin{array}{c}\text { Unidad } \\
\text { del } \\
\text { Milenio } \\
\text { Sayausi }\end{array}$ & $\begin{array}{c}\text { Unidad } \\
\text { del } \\
\text { Milenio } \\
\text { Manuel J. } \\
\text { Calle }\end{array}$ & $\begin{array}{l}\text { Unidad } \\
\text { Sagrados } \\
\text { Corazones }\end{array}$ & $\begin{array}{c}\text { Unidad } \\
\text { Santa } \\
\text { Mariana } \\
\text { de Jesús }\end{array}$ \\
\hline $\begin{array}{l}1 \text { ¿Cuál es tu } \\
\text { motivación diaria? }\end{array}$ & La familia & $68.2 \%$ & $53.4 \%$ & $45 \%$ & $47.1 \%$ & $46.7 \%$ & $51.3 \%$ \\
\hline $\begin{array}{l}\text { 2. ¿Qué te gustaría } \\
\text { estudiar en la } \\
\text { Universidad? }\end{array}$ & Medicina & $13.6 \%$ & $34.5 \%$ & $12.5 \%$ & $20.6 \%$ & $33.3 \%$ & $43.4 \%$ \\
\hline $\begin{array}{l}\text { 3. ¿Cuál es tu } \\
\text { sueño más grande } \\
\text { y cómo piensas } \\
\text { lograrlo? }\end{array}$ & $\begin{array}{l}\text { Ser } \\
\text { profesional }\end{array}$ & $75 \%$ & $65.5 \%$ & $87.5 \%$ & $66.2 \%$ & $71.7 \%$ & $90.8 \%$ \\
\hline $\begin{array}{l}\text { 4. ¿Cuál crees que } \\
\text { es tu identidad? }\end{array}$ & Mestizo & $50 \%$ & $43.1 \%$ & $42.5 \%$ & $38.2 \%$ & $71.7 \%$ & $96.1 \%$ \\
\hline $\begin{array}{l}\text { 5. ¿Cuáles son las } \\
\text { características de } \\
\text { tu identidad? }\end{array}$ & $\begin{array}{l}\text { Los rasgos } \\
\text { físicos y } \\
\text { característica } \\
\text { s de su } \\
\text { personalidad. }\end{array}$ & $59.1 \%$ & $22.4 \%$ & $32.5 \%$ & $26.5 \%$ & $53.3 \%$ & $78.9 \%$ \\
\hline $\begin{array}{l}\text { 6. ¿Te identificas } \\
\text { como ecuatoriano? }\end{array}$ & $\mathrm{Si}$ & $86.4 \%$ & $93.1 \%$ & $95 \%$ & $95.6 \%$ & $98.3 \%$ & $100 \%$ \\
\hline $\begin{array}{l}\text { 7. ¿Te gustaría } \\
\text { trabajar de } \\
\text { Ejecutivo o } \\
\text { Agricultor? }\end{array}$ & Ejecutivo & $61.4 \%$ & $55.2 \%$ & $42.5 \%$ & $33.8 \%$ & $51.7 \%$ & $39.5 \%$ \\
\hline $\begin{array}{l}\text { 8. ¿Qué trabajo } \\
\text { piensas que es } \\
\text { más fácil realizar? }\end{array}$ & $\begin{array}{l}\text { Gerente de } \\
\text { una empresa }\end{array}$ & $38.6 \%$ & $62.1 \%$ & $70 \%$ & $61.8 \%$ & $76.7 \%$ & $67.1 \%$ \\
\hline $\begin{array}{l}\text { 9. ¿En qué rango } \\
\text { de estudiante te } \\
\text { encuentras? }\end{array}$ & Bueno & $52.3 \%$ & $55.2 \%$ & $80 \%$ & $61.8 \%$ & $55 \%$ & $35.5 \%$ \\
\hline $\begin{array}{l}\text { 10. ¿Qué profesión } \\
\text { /oficios consideras } \\
\text { que es mejor? }\end{array}$ & Médico & $56.8 \%$ & $58.6 \%$ & $30 \%$ & $52.9 \%$ & $61.7 \%$ & $64.5 \%$ \\
\hline $\begin{array}{l}\text { 11. ¿Qué tipo de } \\
\text { preparación } \\
\text { académica debe } \\
\text { tener tu docente } \\
\text { de tu Unidad } \\
\text { Educativa? }\end{array}$ & Magíster & $61.4 \%$ & $51.7 \%$ & $35 \%$ & $54.4 \%$ & $35 \%$ & $30.3 \%$ \\
\hline
\end{tabular}


Globalización y aculturación: la influencia de los medios de comunicación en la Educación Intercultural de Ecuador

\begin{tabular}{|c|c|c|c|c|c|c|c|}
\hline $\begin{array}{l}\text { 12. ¿Reconoce las } \\
\text { siguientes } \\
\text { películas? }\end{array}$ & \begin{tabular}{|l|} 
Reconocen \\
tanto las \\
películas \\
ecuatorianas \\
como las \\
extranjeras
\end{tabular} & $75 \%$ & $67.2 \%$ & $47.5 \%$ & $82.4 \%$ & $86.7 \%$ & $75 \%$ \\
\hline $\begin{array}{l}\text { 13. ¿Identifica a } \\
\text { los siguientes } \\
\text { deportistas? }\end{array}$ & \begin{tabular}{|l|} 
Reconocen a \\
deportistas \\
ecuatorianos \\
como \\
extranjeros. \\
\end{tabular} & $68.2 \%$ & $37.9 \%$ & $22.5 \%$ & $23.5 \%$ & $35 \%$ & $3.9 \%$ \\
\hline $\begin{array}{l}\text { 14. ¿Reconoce a } \\
\text { los siguientes } \\
\text { artistas y } \\
\text { compositores? }\end{array}$ & \begin{tabular}{|l|} 
Reconocen a \\
artistas y \\
compositores \\
extranjeros
\end{tabular} & $84.1 \%$ & $94.1 \%$ & $77.5 \%$ & $83.8 \%$ & $76.7 \%$ & $85.5 \%$ \\
\hline $\begin{array}{l}\text { 15. ¿Qué } \\
\text { tendencia de moda } \\
\text { te atrae más? }\end{array}$ & $\begin{array}{l}\text { Les atraen la } \\
\text { tendencia de } \\
\text { moda de } \\
\text { Estados } \\
\text { Unidos } \\
\end{array}$ & $56.8 \%$ & $75.9 \%$ & $70 \%$ & $64.7 \%$ & $83.3 \%$ & $65.8 \%$ \\
\hline $\begin{array}{l}\text { 16. ¿Qué idioma te } \\
\text { gusta hablar? }\end{array}$ & Español & $54.5 \%$ & $60.3 \%$ & $65 \%$ & $64.7 \%$ & $68.3 \%$ & $77.6 \%$ \\
\hline $\begin{array}{l}\text { 17. ¿Qué prefieres } \\
\text { degustar? }\end{array}$ & $\begin{array}{l}\text { Prefieren las } \\
\text { salchipapas, } \\
\text { el hot dog. }\end{array}$ & $15.9 \%$ & $17.2 \%$ & $32.5 \%$ & $11.8 \%$ & $3.3 \%$ & $9.2 \%$ \\
\hline $\begin{array}{l}\text { 18. ¿Qué bebida } \\
\text { prefieres? }\end{array}$ & Coca Cola & $65.9 \%$ & $70.7 \%$ & $70 \%$ & $67.6 \%$ & $66.7 \%$ & $72.4 \%$ \\
\hline $\begin{array}{l}19 . \text { ¿Conoce la } \\
\text { ubicación a los } \\
\text { Pueblos y } \\
\text { Nacionalidades del } \\
\text { Ecuador? } \\
\end{array}$ & No responden & $65.9 \%$ & $82.8 \%$ & $72.5 \%$ & $75 \%$ & $90 \%$ & $82.2 \%$ \\
\hline $\begin{array}{l}\text { 20. ¿Reconoce a } \\
\text { qué país } \\
\text { pertenecen las } \\
\text { siguientes } \\
\text { banderas? }\end{array}$ & $\begin{array}{l}\text { Reconocen } \\
\text { las banderas } \\
\text { de Colombia, } \\
\text { Ecuador, } \\
\text { EEUU, } \\
\text { Venezuela }\end{array}$ & $100 \%$ & $98.2 \%$ & $100 \%$ & $97.1 \%$ & $100 \%$ & $100 \%$ \\
\hline $\begin{array}{l}21 . \text { ¿Reconoce y } \\
\text { escribe el nombre } \\
\text { de las siguientes } \\
\text { culturas? }\end{array}$ & $\begin{array}{l}\text { Reconocen } \\
\text { las culturas } \\
\text { extranjeras }\end{array}$ & $56.8 \%$ & $60.3 \%$ & $32.5 \%$ & $52.9 \%$ & $66.7 \%$ & $85.5 \%$ \\
\hline $\begin{array}{l}\text { 22. ¿Conoce el } \\
\text { significado de las } \\
\text { siguientes frases? }\end{array}$ & \begin{tabular}{|l|} 
Conocen \\
únicamente el \\
significado de \\
Sumak \\
Kawsay. \\
\end{tabular} & $59.1 \%$ & $79.3 \%$ & $75 \%$ & $23.5 \%$ & $36.7 \%$ & $51.3 \%$ \\
\hline $\begin{array}{l}\text { 23. ¿Conoce el } \\
\text { lugar donde se } \\
\text { realizan las } \\
\text { siguientes Fiestas } \\
\text { Populares en el } \\
\text { Ecuador? } \\
\end{array}$ & $\begin{array}{l}\text { Si conocen el } \\
\text { lugar donde } \\
\text { se realizan } \\
\text { las Fiestas } \\
\text { Populares en } \\
\text { Ecuador } \\
\end{array}$ & $45.5 \%$ & $41.4 \%$ & $37.5 \%$ & $38.2 \%$ & $53.3 \%$ & $57.9 \%$ \\
\hline $\begin{array}{l}\text { 24. ¿Conoce a qué } \\
\text { país pertenecen } \\
\text { las siguientes } \\
\text { Fiestas } \\
\text { Tradicionales } \\
\text { extranjeras? } \\
\end{array}$ & Si conocen & $100 \%$ & $98.3 \%$ & $95 \%$ & $97.1 \%$ & $98.3 \%$ & $96.1 \%$ \\
\hline $\begin{array}{l}\text { 25. ¿Conoce a qué } \\
\text { nacionalidad } \\
\text { pertenecen los } \\
\text { siguientes géneros } \\
\text { musicales? }\end{array}$ & \begin{tabular}{|l|} 
La mayoría \\
de \\
estudiantes \\
no conocen a \\
qué \\
nacionalidad \\
pertenecen \\
\end{tabular} & $40.9 \%$ & $48.3 \%$ & $5 \%$ & $39.7 \%$ & $15 \%$ & $57.9 \%$ \\
\hline
\end{tabular}




\begin{tabular}{|c|c|c|c|c|c|c|c|}
\hline & $\begin{array}{l}\text { los géneros } \\
\text { musicales del } \\
\text { Ecuador. }\end{array}$ & & & & & & \\
\hline $\begin{array}{l}\text { 26. ¿Qué prefieres } \\
\text { aprender quichua } \\
\text { o inglés? }\end{array}$ & Inglés & $68.2 \%$ & $87.9 \%$ & $80 \%$ & $60.3 \%$ & $81.7 \%$ & $77.6 \%$ \\
\hline $\begin{array}{l}\text { 27. ¿Reconoce a } \\
\text { las siguientes } \\
\text { mujeres? }\end{array}$ & $\begin{array}{l}\text { Reconocen a } \\
\text { las mujeres } \\
\text { ecuatorianas } \\
\text { pero } \\
\text { desconocen } \\
\text { su legado. }\end{array}$ & $52.3 \%$ & $58.6 \%$ & $30 \%$ & $25 \%$ & $45 \%$ & $97.4 \%$ \\
\hline $\begin{array}{l}\text { 28. ¿Qué } \\
\text { actividades } \\
\text { realizas para } \\
\text { conservar el } \\
\text { ecosistema? }\end{array}$ & Reciclar & $86.4 \%$ & $74.1 \%$ & $65 \%$ & $73.5 \%$ & $86.7 \%$ & $90.8 \%$ \\
\hline $\begin{array}{l}\text { 29. ¿Qué tipos de } \\
\text { alimentos } \\
\text { consumes? }\end{array}$ & $\begin{array}{l}\text { Alimentos } \\
\text { orgánicos }\end{array}$ & $61.4 \%$ & $67.2 \%$ & $80 \%$ & $82.4 \%$ & $68.3 \%$ & $81.6 \%$ \\
\hline $\begin{array}{l}\text { 30. ¿Qué } \\
\text { economía } \\
\text { practican en el } \\
\text { barrio dónde } \\
\text { vives? }\end{array}$ & $\begin{array}{l}\text { La economía } \\
\text { que se } \\
\text { practica en } \\
\text { los barrios } \\
\text { donde viven } \\
\text { los } \\
\text { estudiantes } \\
\text { es la } \\
\text { consumista }\end{array}$ & $52.3 \%$ & $37.9 \%$ & $72.5 \%$ & $47.1 \%$ & $31.7 \%$ & $48.7 \%$ \\
\hline $\begin{array}{l}\text { 31. Escriba un mito } \\
\text { o una leyenda del } \\
\text { Ecuador }\end{array}$ & $\begin{array}{l}\text { La mayoría } \\
\text { conocen la } \\
\text { leyenda de } \\
\text { Cantuña y } \\
\text { Mari angula. }\end{array}$ & $36.4 \%$ & $31 \%$ & $37.5 \%$ & $27.9 \%$ & $21.7 \%$ & 46.1 \\
\hline
\end{tabular}

Fuente: Elaboración propia

Si bien la Tabla 2 representa una reducción y simplificación de los datos empíricos obtenidos durante la investigación -que originalmente fueron clasificados en 31 tablas con los porcentajes de las respuestas estudiantiles-, nos permite corroborar que los medios de comunicación monoculturizan el imaginario colectivo y homogenizan la identidad de los adolescentes. La información obtenida nos permite afirmar que existe una causalidad directa entre la influencia de los medios de comunicación y pérdida de los rasgos culturales identitarias de Ecuador. En este sentido, es urgente repensar los procesos de interculturalización de los pueblos frente a los procesos de aculturación de la globalización en los contextos educativos.

Al realizar un análisis comparativo, se observan comportamientos interesantes entre los estudiantes de colegios públicos, escuelas privadas y del milenio. A grandes rasgos, los estudiantes de las Unidades Educativas Públicas consideran relevante la preparación académica del cuerpo docente y los rangos de calificación académica. También reconocen las imágenes que el cuestionario muestra sobre películas, deportistas y artistas nacionales y extranjeros. Conocen las fiestas populares del país y sus géneros musicales, y tienen una preferencia hacia la economía de consumo. 
En lo referente a las preferencias de los estudiantes de las Unidades Educativas del Milenio, responden mayoritariamente que se sienten atraídos por las tendencias de moda de Estados Unidos. Si bien prefieren el idioma español, reconocen más las culturas extranjeras que las propias. Además, destaca que la gran mayoría desea formarse para ser gerentes de una empresa. Por otro lado, los estudiantes de las Unidades Educativas Privadas responden que la familia tiene un papel importante, que desean estudiar medicina o profesionales neoliberales de éxito. Consideran que los rasgos físicos son los que definen su identidad (pregunta 5), por lo que se autodefinen como mestizos. También responden que prefieren la Coca-Cola antes que las bebidas locales de las comunidades.

Al profundizar en el estudio comparativo, se pone de manifiesto que el lugar donde están ubicados los colegios determina, en gran medida, la percepción de desarrollo económico de los estudiantes (pregunta 30). Otra variable a considerar en futuras investigaciones es cómo las familias convierten el capital económico en capital cultural, puesto que se evidencia un mayor conocimiento de los géneros musicales (pregunta 25) o de las figuras femeninas de la cultura ecuatoriana (pregunta 27) en aquellos estudiantes de colegios privados cuyas familias tienen mayores ingresos. Sin embargo, es motivo de análisis el alto porcentaje estudiantil de los seis colegios no responde sobre la ubicación de los pueblos y nacionalidades de Ecuador (pregunta 19), lo que significa que, o bien no existe interés por aprender de los ancestros o bien no aprendieron esos conocimientos en los colegios. En contraste, la pregunta 20 muestra que casi todos reconocen las banderas de países extranjeros.

En su conjunto, las respuestas de los estudiantes al cuestionario muestran cómo los medios de comunicación trascienden el ámbito psicológico-social para propagar las tendencias publicitarias y comerciales de las modas creadas por las grandes corporaciones: teniendo una fuerte influencia en la construcción identitaria. Por eso se concluye con la necesidad urgente de reforzar la identidad en los contenidos curriculares, en las políticas públicas educativas y en los planes nacionales de desarrollo para conseguir revalorizar la identidad plural de Ecuador.

\section{Discusión}

De la información recolectada con la encuesta, se puede interpretar que existen diversos problemas fundamentales que permiten la aculturación de los fenómenos globalizadores de los medios de comunicación. En primer lugar, las familias y comunidades se enfrentan a la pérdida de interés que los adolescentes tienen con respecto a las costumbres, prácticas, hábitos, ritos y cosmovisiones. En segundo lugar, se evidencia la falencia del sistema educativo, cuyo currículo nacional y perfil profesional docente no están preparados académicamente para enfrentar la homogenización de la monocultura difundida por internet, redes sociales, TV, radio y prensa. Y, en tercer lugar, y más preocupante, la carencia de cualquier tipo de presión 
o mecanismo de control hacia las corporaciones responsables de crear contenidos publicitarios.

Por todos estos motivos, es necesario integrar en el Currículo Nacional de Bachillerato General Unificado (BGU) estrategias educativas, didácticas y pedagógicas cuyo enfoque decolonial, intercultural, complejo y transdisciplinar rompa estas tendencias globalizadoras. Si bien el enfoque de competencias, habilidades y destrezas que establece el currículo del BGU busca promover una educación intercultural crítica e inclusiva en Ecuador, no se puede ignorar que la identidad ecuatoriana se ve afectada por dichas tendencias. Cuando se le pregunta a un adolescente: ¿qué significa ser ecuatoriano? ¿Qué raíces culturales forma parte de ti? Se constata un limbo identitario que no les permite autodefinirse por los conflictos que le generan las influencias globalizadoras. Hay que repensar el currículo y las políticas públicas educativas para reforzar y fortalecer los procesos de interculturalización.

Aquí cabe utilizar las herramientas existentes hasta la fecha, como es el 'Plan Nacional de Desarrollo 2017-2021 - Toda una Vida' publicado por el Gobierno Nacional del Ecuador, cuyo objetivo 2 reafirma la interculturalidad y plurinacionalidad mediante un reconocimiento plural:

El sentido de identidad es fundamental, no solo para la construcción del nacionalismo ecuatoriano, sino para la creación de un diálogo de saberes en espacios de encuentro intercultural e intergeneracional. Se trata de la demanda por un nuevo escenario social. En este, el Estado garantiza protección a: los derechos colectivos de pueblos y nacionalidades, incluidos los pueblos en aislamiento voluntario -a los cuales se debe salvaguardar en el respeto a su autodeterminación-; a los derechos de las personas en situación de movilidad humana, de las comunidades sexogenéricas diversas, de las culturas urbanas, entre otras. En esta misma línea, se promueven las potencialidades y expresiones artísticas; los espacios físicos y simbólicos de intercambio cultural; los saberes ancestrales, su ritualidad, las plantas e instrumentos simbólicos de poder y la memoria histórica que guardan; el patrimonio tangible e intangible relacionado con las personas, comunidades y colectivos. Todo esto forma parte de la materialización del proyecto plurinacional e intercultural (Senplades, 2017, p.60).

Este documento promueve la revalorización de identidades plurales dando cabida a nuevas formas de identificación. Pone de manifiesto que la identidad es imprescindible para reafirmar la identidad nacional y el sentimiento patriótico, que se fundamenta en un diálogo de saberes que abre las puertas para trascender hacia nuevos escenarios sociales interculturales. Pero vemos que llevar esta teoría a la práctica no resulta tan fácil, por lo que es necesario continuar discutiendo e interpretando cómo la hibridación identitaria se puede construir a través de una negociación de la diferencia, ya que todas las culturas son hibridaciones de culturas 
anteriores. Dado que la globalización usa las TIC para generar procesos de aculturación, la interculturación debe ser promovida en escuelas y comunidades para generar procesos de arraigo cultural y sentido de pertenencia (Hartford, 2010). El reto está en 'apropiarse' de estos nichos de diseminación de las TIC, para interculturalizar de manera tecnológica y digital.

En este sentido Simon (2008) explica que la identidad es una construcción social, psicológica, filosófica, antropológica y educativa que permite a los individuos autodefinirse a sí mismos. Como espacios de formación humana, las escuelas tienen la responsabilidad de co-construir la identidad plural de los estudiantes mediante el fomento de un pensamiento crítico y creativo. De ahí la necesidad en transgredir los modelos educativos tradicionales que reproducen y perpetúan el imaginario colectivo impuesto por los grupos de poder hegemónico (Young, 2011). Para Foucault (1992), la educación escolarizada invisibiliza los saberes locales, al afirmar que "saberes sujetos, es una serie de saberes que habían sido descalificados como no competentes $\mathrm{o}$ insuficientemente elaborados; saberes ingenuos, jerárquicamente inferiores, por debajo del nivel de conocimiento o cientificidad requerido" (p.18).

Desde un pensamiento crítico, Freire (1997) advierte que las escuelas son reproductoras burocráticas de la desigualdad opresiva, eliminando los saberes propios de cada estudiante. A su vez, López (2009) propone la creación de sistemas educativos propios construidos 'desde abajo'. En esta misma línea de pensamiento, Meléndez (2012) postula una visión educativa que fusiona los conocimientos científicos con los saberes comunitarios, con el fin de enfrentar la aculturación de la globalización desde el diálogo inter-epistemológico.

Al profundizar en la interculturalidad crítica, Walsh (2012) explica que se trata de un "proyecto político -social-epistémico-ético y herramienta pedagógica, ambos con el afán de una praxis educativa encaminada hacia lo decolonial" (p. 156). Esta visión crítica de la interculturalidad requiere una praxis decolonial en la práctica político-educativa dirigida hacia la transformación de las estructuras, las instituciones y las relaciones sociales. Por consiguiente, apostar por políticas públicas de educación intercultural permitirá construir el camino hacia una transformación del imaginario colectivo.

Sin embargo, cuando se analizan e interpretan los planes de estudio y el currículo del BGU de Ecuador, se observa que se privilegian los conocimientos científicos y se marginan los saberes comunales. También se observan prácticas educativas descontextualizadas que no incluyen los saberes, prácticas y cosmovisiones de los pueblos, culturas y nacionalidades, generándose, así, una pérdida identitaria. No cabe duda de que la educación intercultural debe desarrollar políticas públicas que revaloricen las identidades plurales de Ecuador. Aquí, Walsh (2006) reflexiona que "la interculturalidad debe ser vista como un proceso de construcción continuo de modos de pensar, estructuras e instituciones" (p.25). 
A su vez, Santos (2010) nos insta a promover diálogos interculturales que combatan la uniformidad de la globalización mediante una ecología de saberes emancipatoria y libertaria. Para este autor, la interculturalidad es un proceso histórico doblemente complejo, porque: a) se trata de transformar relaciones verticales entre culturas en relaciones horizontales, o sea, someter un largo pasado a una apuesta de futuro diferente; y b) no puede conducir al relativismo, toda vez que la transformación ocurre en un marco constitucional determinado. En suma, esta discusión e interpretación de los datos recogidos durante la investigación nos permite comprender que la identidad intercultural de Ecuador es un proceso en continua construcción. Un proceso continuo que debe enfrentar la aculturación monocultural y colonial de la globalización, para fortalecer la interculturación desde principios de equidad, diálogo, justicia social, igualdad de oportunidades y convivencia armónica.

\section{Conclusiones}

Según advierten los expertos críticos en comunicación Herman y McChesney (2004), la década de 1980 se caracterizó por la ola de 'liberalización' mundial que privatizó empresas estatales, por la desregulación de las empresas privadas y porque las iniciativas de los Estados de bienestar se redujeron. Esto dio lugar a una nueva etapa del capitalismo corporativo global, originándose las bases de un sistema de medios de comunicación globales. De acuerdo al informe de Reporteros sin Fronteras (2016), los medios de comunicación se han convertido, en las últimas décadas, en los misioneros del capitalismo global: sirviendo a los intereses económicos de sus dueños, en su mayoría magnates y corporaciones transnacionales. Este informe denuncia que en la década de 1980 había cincuenta grandes empresas estadounidenses que controlaban el $90 \%$ del sector de comunicación global, y en la actualidad este poder se concentra en tan solo seis (RsF, 2016).

Por ello, este sistema de oligopolios en el ámbito de los medios de comunicación globales representa el reflejo del triunfo del mercado global, fundamentado en la monocultura, la aculturación y la homogenización del imaginario colectivo. La manipulación de masas causa interés a lo largo de esta investigación. Por eso es urgente repensar las políticas públicas de educación en Ecuador. Los estudiantes forman parte de esta sociedad globalizada cuyos medios de comunicación e industrias culturales bombardean constantemente con publicidad para el consumo masivo. Como se ha demostrado en esta investigación, esta influencia de los medios de comunicación en la educación intercultural de Ecuador trae grandes peligros para los procesos de construcción y desarrollo de la identidad de estudiantes adolescentes.

La aculturación del capitalismo globalizado se impone sobre la cultura autóctona local de los pueblos y comunidades. Por este motivo, es urgente profundizar en el debate de la construcción identitaria desde una visión emancipadora 
que conciba la identidad como un fenómeno socio-espacial-comunicacional. Esta visión implica una reconstrucción del concepto de identidad que permita la deconstrucción de conceptos y significados. También requiere nuevos espacios académicos que incluyan los retos y desafíos de la 'identidad digital' que emerge con el uso masificado de las redes sociales.

A su vez, se concluye que las escuelas deben contextualizar sus prácticas educativas de acuerdo a la idiosincrasia cultural de las comunidades, familias, estudiantes y docentes. Para reivindicar y revalorizar la pluralidad identitaria es necesario transformar la lógica institucional de las escuelas, repensar los conocimientos curriculares de las materias, fortalecer el perfil profesional docente, promover competencias interculturales con los estudiantes y trabajar de forma comprometida en vinculación con las comunidades. Los riesgos de aculturación de la globalización se han fortalecido con los dispositivos digitales, tecnológicos e informáticos masificados (UNESCO, 2020). Esto provoca una mayor subordinación colonial a la lógica de mercado que difunden los medios de comunicación, por lo que se invita a los lectores a seguir investigando en esta línea de trabajo. Es necesario construir una educación liberadora, cuyo espíritu crítico emancipador logre desacreditar los estereotipos identitarios de la globalización.

Es un producto del proyecto de investigación "Filosofía de la Educación: Reflexiones para la formación pedagógica transdisciplinar aprobado por la Universidad Nacional de Educación (UNAE) Ecuador.

\section{Referencias}

Aguado, T; Melero, H., y Gil-Jaurena, I. (2018). Espacios y prácticas de participación ciudadana. Propuestas educativas desde una mirada intercultural. RELIEVE, 24(2), art. M3. doi: http://doi.org/10.7203/relieve.24.2.13194

Barbero, J. y Rey G. (2000), "Los ejercicios del ver: hegemonía audiovisual y ficción televisiva: hegemonía audiovisual y ficción televisiva", Signo y pensamiento 19, núm. 36: 129-30.

Becerra, M., y Mastrini, G. (2017). La concentración infocomunicacional en América Latina (2000-2015): nuevos medios y tecnologías, menos actores. Bernal: Universidad Nacional de Quilmes; Observacom.

Berger, P. y Huntintong, S. (2002). Globalizaciones múltiples: la diversidad cultural en el mundo contemporáneo. Barcelona: PAIDÓS.

Castells, M. (2010). The information age: economy, society, and culture. Volume II. The Power of Identity. New Jersey: Wiley-Blackwell.

Castells, M. (2013). Communication power. Oxford: Oxford University Press.

Castells, M., y Hall, P. (2014). Technopoles of the World. The making of 21 ${ }^{\text {st }}$ Century Industrial Complexes. London: Routledge. 
Chomsky, N. (2002) A World Without War? Reflections on Globalization and Antiglobalization, Canadian Journal of Development Studies, 23 (3), pp. 493511, https://doi.org/10.1080/02255189.2002.9668883

Collado, J. y Apolo, D. (2018). Ética y valores: una perspectiva transdisciplinar desde la ecología de saberes. Rodríguez, M. y García, W. (coord..), Otra mirada desde la práctica educativa. Educación, ética y valores. Azogues: Editora UNAE, pp. 6179.

Cuche, D. (2007). La noción de cultura en las ciencias sociales. Buenos Aires: Nueva Visión.

Derrida, J. (2021). Dissemination. Chicago: The University of Chicago Press.

Dietz, G. (2012). Multiculturalismo, interculturalidad y diversidad en educación. Una aproximación antropológica. México: Fondo de Cultura Económica

Dussel, E. (2013). Ethics of Liberation. In the Age of Globalization and Exclusion. Duke University Press, London.

Echeverría, B. (1995). La Identidad evanescente. Las ilusiones de la Modernidad (pp. 55-75). México D.F.: Las ilusiones del equilibrista; UNAM.

Estermann, J. (2014). "Colonialidad, descolonización e interculturalidad. Apuntes desde la Filosofíalntercultural". Polis Revista de la Universidad Bolivariana, 38 , p. 347-368

Foucault, M. (1992). Genealogía del racismo. Madrid: La Piqueta.

Freire, P. (1997). La educación como práctica de la libertad. México DF: Siglo XXI editores.

Gómez, H. (1999). Educación la agenda del siglo XXI: Hacia un desarrollo humano. Bogotá: PNUD-TM Editores.

González, J. (2020). Medios de comunicación, ¿al servicio de quién? Buenos Aires: CLACSO. http://biblioteca.clacso.edu.ar/clacso/gt/20200423054514/Mediosde-comunicacion.pdf

Gupta, N. (2012), "The impact of globalization on consumer acculturation: A study of urban, educated, middle class Indian consumers", Asia Pacific Journal of Marketing and Logistics, 24 (1), pp. 41-58.

https://doi.org/10.1108/13555851211192696

Hartford, P. (2010). Collaborative Acculturation: the role of community in the process of becoming intercultural. PhD thesis dissertation. Capella University.

Haucap, J., y Heimeshoff, U. (2014). Google, Facebook, Amazon, eBay: Is the Internet driving competition or market monopolization?. International Economics and Economic Policy, 11, pp. 49-61.

https://doi.org/10.1007/s10368-013-0247-6

Haydon, D. (2020). Detained children: Vulnerability, violence and violation of rights. International Journal for Crime, Justice and Social Democracy 9(4): 16-30. https://doi.org/10.5204/ijcjsd.1687 
Instituto Nacional de Estadística y Censo (INEC) (2010). Censo 2010. Población y vivienda. Una historia para ver y sentir. Quito: INEC.

Instituto Nacional de Estadística y Censo (INEC) (2019). Tabulados de Tecnología de la Información y Comunicación. Encuesta nacional multipropósito de hogares 2019. Quito: INEC.

Klein, N. (2019). On Fire: The (Burning) Case for a Green New Deal. New York: Pinguin.

Levitskaya, A. y Fedorov, A. (2020). Typology and Mechanisms of Media Manipulation. International Journal of Media and Information Literacy, 5(1): 69-78.

López, E. (2009). "Interculturalidad, Educación y política en América Latina: perspectivas desde el sur, pistas para un investigación comprometida y dialogal.", en Luis Enrique López, Interculturalidad, Educación y Ciudadanía. La paz: Plural, pp. 130-218.

McCarthy, S. (2017). Are Social Networking Sites Controlling Your Mind?. Scientific American. Available at: https://www.scientificamerican.com/article/are-socialnetworking-sites-controlling-your-mind/ [Accessed 22 Feb. 2021].

Meléndez, J. (2012). "La escuela en la disputa política y territorial", ponencia presentada en el Pre-Congreso Alasru, 1214 de noviembre, San Cristóbal de Las Casas, Chiapas, México.

Mignolo, W. (2012). Local Histories/Global Designs. Coloniality, Subaltern Knowledges, and Border Thinking. Princeton University Press, Princeton.

Muñoz, G. (2016). Comunicación-educación en la cultura para América Latina. Desafíos y nuevas comprensiones. Bogotá: UNIMINUTO.

Naval, C. (2001). La educación (moral y cívica) en una sociedad globalizada. Estudios Sobre Educación, número 1ํ: Monográfico Globalización y educación, 21-36.

Ozer, S., Bertelsen, P., Singla, R., y Schwartz, S. J. (2017). Grab Your Culture and Walk with the Global: Ladakhi Students' Negotiation of Cultural Identity in the Context of Globalization-Based Acculturation. Journal of Cross-Cultural Psychology, 48(3), 294-318. https://doi.org/10.1177/0022022116687394

Pesántez, F., Álvarez, L., Torres, A. (coord.) (2021). COVIDA-20. Una coalición educativa para enfrentar la pandemia. Lima: Pearson.

Quijano, A. (2000). Coloniality of Power and Eurocentrism in Latin America. International Sociology, 15 (2), 215-232. doi: 10.1177/0268580900015002005

Reporteros sin Fronteras (2016). Medios de comunicación. Los oligarcas se van de compras. Paris: RsF. https:/www.rsf-es.org/wpcontent/uploads/attachments/2016 07 RSF INFORME OLIGARCAS ESP.p $\underline{\mathrm{df}}$

Reports and Data (2020). Big Data and Data Engineering Services Market to Reach USD 144.12 Billion By 2026. https://www.reportsanddata.com/pressrelease/global-big-data-and-data-engineering-services-market 
Rivera-Cusicanqui, S (2010). Ch'ixinakax utxiwa: una reflexión sobre prácticas y discursos descolonizadores. Buenos Aires: Tinta Limón.

Santos, B. (2010). Descolonizar el Saber, Reinventar el poder. Montevideo: Ediciones Trilce.

Santos, B. (2020). La cruel pedagogía del virus. Madrid: Ediciones AKAL.

Senplades (2017). Plan Nacional de Desarrollo 2017-2021. Toda una Vida. Secretaría Nacional de Planificación y Desarrollo. Quito - Ecuador.

Shiva V. (1993). Monocultures of the Mind-Understanding the Threats to Biological and Cultural Diversity. Indian Journal of Public Administration, 39(3):237-248. https://10.1177/0019556119930304

Shiva, V. y Shiva, K. (2020). Oneness vs. the 1\%: shattering Illusions, Seeding Freedom. New Delhi: Chelsea Green Publishing.

Simon, B. (2008). Identity in Modern Society: A Social Psychological Perspective. Cornwall: Blackwell Publishing.

Stiglitz, J., Sen, A. y Firoussi, J. (2010). Mis-Measuring Our Lives. Why GDP Doesn't Add Up. The report by the Commission on the Measurement of Economic Performance and Social Progress. The New Press, New York.

Tubino, F. (2005). La praxis de la interculturalidad en los Estados Nacionales Latinoamericanos, Cuadernos Interculturales, vol. 3, n 5, pp. 83-96.

UNESCO (2020). The Digital Transformation of Education: Connecting Schools, Empowering Learners. Paris: UNESCO. https://unesdoc.unesco.org/ark:/48223/pf0000374309

Van Dijk, T. (2011). Discourse and communication: New approaches to the analysis of mass media discourse and communication. Berlin: W de G.

Vivanco, A. (2020). Teleducación en tiempos de COVID-19: brechas de desigualdad. CienciAmérica, 9(2),166-175.

Wallerstein, I. (2011). The Modern World-System I. Capitalist Agriculture and the Origins of the Eropean World-Economy in the Sixteenth Century. Berkeley: University of California Press.

Waldmüller, J. (2016). "Aportes de la filosofía intercultural al debate ecuatoriano: un acercamiento a partir de la teoría de los centrismos". Gómez, J. (ed.). Repensar la interculturalidad, pp. 72-105. Guayaquil: Universidad de las Artes.

Walsh, C. (2006) Interculturalidad, conocimientos y (de)colonialidad. En T. Almorín Orogpa, et al. (Eds.), Política e interculturalidad en la educación. Memoria del II encuentro multidisciplinario de educación intercultural CEFIA-UIC-CGEIB. México: Coordinación General de Educación Intercultural y Bilingüe, Instituto Internacional de Filosofía.

Walsh, C. (2012). Interculturalidad crítica y (de)colonialidad. Ensayos desde AbyaYala. Quito: AbyaYala. 
Yalán, E. (2019). Aproximación y análisis semiótico del consumo e hiperconsumo en el discurso publicitario. Universidad Peruana de Ciencias Aplicadas (UPC), Lima, Perú. https://repositorioacademico.upc.edu.pe/handle/10757/626031

Young, M. (2011). The Rise of the Meritocracy. New Jersey: Taylor \& Francis.

Zebadúa, J. (2011). Cultura, identidades y transculturalidad. Apuntes sobre la construcción identitaria de las juventudes indígenas. LiminaR vol.9, n.1, pp.36-47. 
